\title{
What Makes People Underestimate the Perceived Impact of Public Service Announcements? The Theoretical Implication for the Third-Person and First-Person Perceptions
}

\author{
By Nam Young Kim* \\ Masudul Karim Biswas ${ }^{\dagger}$
}

\begin{abstract}
What makes people undervalue the impact of health campaign messages that promote positive behavioral changes? Using the Extended Parallel Process Model's (EPPM) rationale, this study explores whether an interaction between individuals' existing self-efficacy and message attributes (i.e., level of fear) can lead to psychological defensiveness, which makes them cognitively undervalue the Public Service Announcements (PSAs). In the context of anti-binge drinking PSA, a 2 (Fear Appeal: High vs. Low) X 2 (Perceived Self-Efficacy: High vs. Low) experiment reveals that participants with low self-efficacy find a greater effect of PSA on others than on themselves if the PSA includes too much threat or fear (i.e., the third-person perception). Conversely, participants who have a high self-efficacy perceive a greater PSA influence on themselves than on others (i.e., the first-person perception) in response to a high fear-arousing PSA. The theoretical implications for the third-person and first-person perceptions as well as practical implications are discussed.
\end{abstract}

Keywords: Third-person/first-person perception, fear appeals, self-efficacy, persuasion

\section{Introduction}

People do not evaluate the effect of socially desirable media content in the same way that they do for socially harmful media content (Cho \& Han, 2004; Duck \& Mullin, 1995; Gunther \& Hwa, 1996). For decades, a number of studies have consistently found that people consider media effects to be greater on others than on themselves (i.e., the third-person perception) in negative media contexts, such as violence and pornography (Davison, 1983; Gunther, 1991; 1995; Rojas, Shah \& Faber, 1996; Salwen, 1998). In contrast, when people are exposed to socially beneficial media content (e.g., Public Service Announcements, PSAs), people tend to estimate that there is a greater media effect on themselves than on others (i.e., the first-person perception) (Cho \& Han, 2004; Gunther \& Hwa, 1996; Henriksen \& Flora, 1999). However, some scholars also note that a certain message made through PSAs could be less acceptable, if it is not perceived as personally relevant to or consistent with individuals' prior beliefs or behaviors (Cohen, Shumate \& Gold, 2007; Duck \& Mullin, 1995; Snyder \& Rouse, 1992). As a result, a decrease of first-person perception or no first-person perception has been reported in the context of PSAs (Duck \& Mullin, 1995; Snyder \& Rouse, 1992). Accordingly, such studies have emphasized the need to further examine the

*Assistant Professor, Department of Mass Communication, Sam Houston State University, USA.

${ }^{\dagger}$ Assistant Professor, Department of Communication, Loyola University Maryland, USA. 
interaction between external message factors, as well as internal psychological factors, that influence people's perceptions of estimated media effects.

To expand the current discussion of third-person as well as first-person perceptions, we particularly focus on a PSA message with a fear appeal that often leads to a different appraisal of the message. Indeed, empirical studies have often reported the ineffectiveness of using fear appeals in the health campaign because of people's defensive tendency toward a fear (Keller \& Block, 1999; Leshner, Bolls, \& Thomas, 2009; Perloff, 2003; Witte \& Allen, 2000). For instance, when college students who are not confident to control their alcohol consumption encounter dire consequences of alcohol abuse (e.g., death) in a PSA, they may perceive the severity of threat and experience the feeling of fear or anxiety, which in turn may motivate them to engage in subsequent defensive behaviors. In response to a fear appeal, such defensive reactions have been observed as a form of message denials, reactance toward messages, and message avoidance (Witte \& Allen, 2000). Applying this notion to the discussion of third-person and firstperson perceptions, it is reasonable to expect that a change in perceived message impacts from self to others can occur as a form of defensive response to feararousing PSAs. However, enough attention was not given in media effects research to identify what circumstances make people underestimate the perceived impact of PSAs that promote their own healthy behaviors and how it occurs (Ten Hoor et al., 2012; Gunther \& Hwa, 1996).

In this point, we investigate whether an interaction between level of fear appeal in PSAs and individuals' confidence to combat a health-related threat plays a role in the perceptions of PSAs' impact on themselves and on others. To test this rationale, this study uses anti-binge drinking PSA messages in an experiment that involves study participants who view a PSA with either a low fear-arousing message or a high fear-arousing message. Through this experiment, we examine the relationship between the study participants' self-efficacy, the perceived message effects on self and on others, and persuasion in the fear-arousing PSAs context. Theoretically, this research provides more in-depth knowledge about what psychological mechanisms lead people to develop a different perception of the message effect at first-person and third-person levels in the fear-arousing health campaign context. Since using fear appeals in public health campaigns does not always guarantee a greater effect, findings of this study can also offer suggestions on how to improve the persuasiveness of a campaign message in practical ways.

\section{Literature Review}

\section{Perceived Message Impacts on Self and on Others}

On the basis of Davison's (1983) original study, the third-person effects perspective posits that people tend to perceive stronger effects of mediamediated messages on others rather than on themselves, referred to as the thirdperson perception (TPP) (Davison, 1983). In particular, when media content is considered to be harmful, empirical studies have shown relatively consistent patterns of third-person perceptions (Gunther, 1991; Henriksen \& Flora, 1999; 
Hoffner \& Buchanan, 2002; Salwen, 1998). One of the salient explanations of how third-person perceptions occur is the discussion of self-enhancement motivation. According to the self-enhancement motivation perspective, individuals prefer to appear at their best and want to maintain their self-esteem (Perloff, 1999). For this reason, people have a tendency to undervalue the impacts of negative media content on themselves to minimize the feeling of losing personal control and to protect their self-esteem. Consistent with this explanation, several empirical studies have found third-person perceptions in the context of violent media content (Hoffner \& Buchanan, 2002), advertising (Henriksen \& Flora, 1999), and negative news stories (Gunther, 1991; Salwen, 1998).

In contrast, when the media message is associated with socially desirable content that has potentially desirable consequences, scholars report the reverse finding - people perceptually overestimate the message's impact on themselves compared to that of others, which is a first-person perception (FPP) (Cho \& Han, 2004; Duck \& Mullin, 1995; Gunther \& Hwa, 1996; Henriksen \& Flora, 1999; Hoorens \& Ruiter, 1996). In the context of PSAs, several scholars noted that individuals tend to generously accept intended persuasion, such as those pertaining to HIV awareness (Duck, Terry, \& Hogg, 1995), smoking cessation (Henriksen \& Flora, 1999), and safe driving (Duck \& Mullin, 1995). Likewise, the nature of the issues involved in PSAs can have an effect on how individuals assess the perceived effects of messages on themselves in relation to others. Unlike TPP, the findings in regard to FPP however have been inconsistent in the context of positive media content (Duck \& Mullin, 1995; Gunther \& Mundy, 1993). Notably, some studies found a greater TPP rather than a FPP in the context of socially desirable health risk messages (Duck \& Mullin, 1995; Gunther \& Mundy, 1993).

As a possible explanation of such inconsistent findings of FPP, some scholars indicate that certain message attributes or message appeals used in the media campaign can play an important role in determining varied perceptions of media influence. For instance, in the context of HIV/AIDS awareness campaigns, Duck et al. (1995) find that weak arguments included in messages enhance participants' TPP, whereas strong arguments included in messages enhance participants' FPP. Another study adds a new perspective on how diverse PSA features - not only fear appeals but also social appeals - can influence participants' perceptions of media impacts (Chock \& Lee, 2005). Particularly, the results show that when people are cognitively overloaded due to the pace of PSA message presentation or fear arousing content, participants' estimated message impact on themselves versus the impact on others becomes similar. Moreover, scholars find that the consistency between individuals' existing beliefs and the media message attributes influences their judgments of FPP (Snyder \& Rouse, 1992). For example, in responding to the anti-smoking PSAs, non-smokers were more likely to evaluate a strong PSA effect on themselves rather than on others, whereas smokers underestimated the effects of the same PSA messages on themselves rather than on others (Chock, Fox, Angelini, Lee, \& Lang, 2003). To sum up, empirical studies have thus far identified individuals' characteristics and message appeals or attributes as significant factors that can interactively influence a change in the self-other perceptual gap. 


\section{Psychological Defensiveness Toward Fear Appeals}

To expand the purview of TPP and FPP, we particularly focus on the defensive avoidance (i.e., "a motivated resistance to the threat of a message," Witte, 1992, p. 322) against a fear appeal that has received a greater attention in health communication and psychological research (Edwards \& Smith, 1996; Keller \& Block, 1999; McKenna \& Williams, 1993). Fear appeals are predominately included in PSAs that generally emphasize "the harmful physical or social consequences of failing to comply with message recommendation" (Hale, Lemieux, \& Mongeau, 1995, p. 459) and often evoke feelings of fear. While earlier studies underscore the importance of using fear appeals in health communication because of their persuasive effectiveness (Freimuth, Hammond, Edgar, \& Monahan, 1990; King \& Reid, 1990), more recent studies warn that individuals tend to activate their defensive techniques to get rid of unpleasant feelings from fear and generate more counterarguments responding to highly feararousing messages (Dillard \& Anderson, 2004; Ten Hoor et al., 2012; Perloff, 2003; Witte \& Allen, 2000).

Particularly, Witte's Extended Parallel Process Model (EPPM) (1992, 1994) provides an in-depth knowledge of fear effects by explaining "not only when and why fear appeals are effective, but also when and why they fail" (Wong \& Cappella, 2009, p. 2). When people are exposed to a fear appeal, the EPPM predicts that people initiate an evaluation of the threat (Witte, Meyer, \& Martell, 2001; Witte, 1992). In this fear-arousing message appraisal, if the threat of an issue is not perceived as relevant or severe, people do not tend to be concerned with such low threat situation, and thus, they are not motivated to respond to the threat (Witte, 1992). However, if people are exposed to highly fear-arousing factual or visual information and perceive the threat as severe or personally relevant, they can become fearful and feel anxiety. In response to a high fear, the EPPM predicts that such arousal of fear/anxiety motivates people to engage in either controlling the threat or controlling the fear, depending on their level of self-efficacy. Scholars have defined one's self-efficacy as "an individual's belief in his or her ability to perform the recommended response to avert the threat" (Cauberghe, De Pelsmacker, Janssens, \& Dens, 2009, p. 277), and it has been considered as one of the major predictors of health-related message processing and behavioral changes (Janz \& Becker, 1984; Stretcher, DeVellis, Becker, \& Rosenstock, 1986; Tucker, Ellickson, \& Klein, 2002; Witte \& Allen, 2000). Regarding the interaction between individuals' self-efficacy and level of fear, the EPPM predicts the following directions: if people evaluate a threat as severe or applicable, but they believe that they are eligible to avoid the threat and prevent the danger, they tend to choose danger control and adopt the recommended behavior or accept the message claims (Witte, 1992). However, if people perceive the hazard of a threat but are not confident to avoid the danger, they tend to engage in fear control to cope with their feelings of fear/anxiety through maladaptive activities, such as denying the severity of the threat and avoiding message elaboration (Witte, 1992; Witte \& Allen, 2000). 


\section{Understanding the Role of Self-Efficacy as a Moderator}

On the basis of the discussion of EPPM and TPP/FPP, we therefore expect in our research that an interaction between a level of fear and individuals' perceived self-efficacy could influence subsequent preventive responses. According to the EPPM's rationale, the perceived severity of an issue motivates a preventive response to a fear appeal, and a perceived self-efficacy determines the nature of the response (Witte, 1992, 1994). In responding to low feararousing PSAs, participants may not perceive the severity of an issue; thus, they will not engage in further appraisal of perceived self-efficacy and preventive responses. Consistent with previous TPP findings in the context of PSAs (Cho \& Han, 2004), it is therefore possible that participants who are exposed to low fear-arousing PSAs perceive a greater PSA impact on themselves than on others regardless of their self-efficacy.

In contrast, in responding to high fear-arousing PSAs, if participants perceive a higher severity of the threat and feel a high level of fear, but they do not have a high confidence to adopt the recommended behaviors to get rid of the threat, they will exhibit some defensive responses. Therefore, we expect that such participants will minimize the acceptance of a highly-threatening message that makes them feel fearful. It is reasonable to expect that they can underestimate the perceived effect of a PSA on themselves even the PSA includes a socially desirable message, such that the difference between perceived media influence on themselves and perceived media influence on others becomes similar, which in turn may decrease the FPP. Likewise, the high threat-low efficacy group can engage in fear control to cope with their feelings of fear; therefore, their adoption of the recommended behavior or acceptance of the PSA message will be relatively weaker (McMahan, Witte, \& Meyer, 1998).

In contrast, in responding to high fear-arousing PSAs, if participants believe that they may have the capability to control their health-related risks and execute the recommended health behaviors, they are more willing to modify their healthrelated behaviors as suggested in the PSA. Therefore, they tend to accept and agree with the health risk messages that underscore the importance of adopting healthy behavior with a high-threatening appeal. In this case, it is possible that they perceive a greater PSA impact on themselves, which in turn may increase the FPP. Moreover, the high threat-high efficacy group can show the other adaptive responses, such as positive attitudes toward messages and higher level of intentions to adopt the recommendation (McMahan et al., 1998).

To test the relationship among level of fear, self-efficacy, perceived message influence, and the other behavioral consequences (i.e., attitudes and behavioral intention), we therefore propose the following hypotheses:

H1a: In the condition of high fear, participants' perceived self-efficacy will determine their estimation of media impact on themselves and on others.

H1b: In the condition of high fear, participants' perceived self-efficacy will determine their attitudes toward messages and their behavioral intention to adopt the recommendation. 


\section{Methodology}

This study has administered a 2 (Level of Fear Appeal: High vs. Low) X 2 (Perceived Self-Efficacy: High vs. Low) experiment among 102 undergraduate and graduate students (ages: 19-47; females 66\%, males 34\%). Earning extra credit was an incentive for students to participate in this study.

\section{Study Procedure}

For this investigation, an invitation e-mail is sent to students who have expressed their interest in study participation. Once students acknowledge the invitation e-mail, they are instructed to read the consent form that described the purpose of the research and the procedure of the study. Participants who agree to participate are randomly assigned to one of two experimental conditions - a high fear appeal or a low fear appeal condition. Once they watch the PSA that includes either a low threat-arousing message or a high threat-arousing message, they are instructed to complete a series of questionnaires which gauge perceived selfefficacy, perceived message effects on themselves and on others (i.e., average college students), attitudes toward message, behavioral intention, a manipulations check, and demographics.

\section{Manipulation of Independent Variable: Level of Fear Appeals}

Fear appeal manipulation. We have manipulated the level of fear by varying "the seriousness of the consequence" in the health risk message content (Keller \& Block, 1999, p. 307). Consistent with the level of fear, the textual messages on the PSA include different alcohol abuse-related concerns. The PSA in a high-fear appeal condition contains highly fearful health-related consequences from alcohol overuse, such as "If you abuse alcohol, you can suffer from serious health problems including increased risk of cancer, neurological disorders, serious memory loss, cardiovascular disease, and even death." The messages with low fear appeal indicate, "If you overuse alcohol, you can suffer from skin damage, poor sleep quality, hangovers, bad breath, and weight gain." The two PSAs are identical in terms of length and presentation of visual images. To assess the effectiveness of manipulation with fear appeals, we have asked participants to evaluate their feelings toward the PSA in terms of whether it is fearful and whether they have felt afraid or scared. A 7-point scale is used with 1 representing "none of this feeling" and 7 representing "a great deal of this feeling" (Dillard \& Anderson, 2004). These items are combined into an index (Cronbach's $\alpha=0.94$ ), with the higher value meaning the greater perception of fear appeal.

\section{Measurement of the Independent Variable}

Participants' perceived self-efficacy is measured using ten 7-point Likerttype scales, such as "I can control myself to reduce alcohol consumption," "I can watch myself to not over drink," and "I can determine the proper amount of alcohol to consume safely." A higher score indicates participants' greater self- 
efficacy belief that their alcohol consumption can be controlled as recommended in the PSAs. The values from the ten questions are averaged to construct an index, perceived self-efficacy (Cronbach's $\alpha=0.89$ ). To examine the effect of perceived self-efficacy, we have identified participants' perceptions of selfefficacy and categorized them as either a relatively high self-efficacy group $(N$ $=53$ ) or a relatively low self-efficacy group $(N=49)$ by using a median split (Median = 5.0, $S D=1.31)$ (McMahan et al., 1998).

\section{Measurements of Dependent Variables}

To estimate the perceived message influence on the self and on average college students, participants are asked to evaluate their perception of PSA impact on themselves as well as on others through one 7-point Likert-type scale ( $1=$ "a greater deal of influence," through $9=$ "no influence at all"). Then, we have calculated the differences between an estimation of media influence on selves and media influence on others by subtracting ratings for PSA effects on self from ratings for PSA effects on others. A negative score indicates the tendency of firstperson perception (FPP) and a positive score indicates a tendency toward thirdperson perception (TPP) (Cho \& Boster, 2008).

In order to measure attitudes toward messages and behavioral intention, participants are asked to evaluate their perception of the messages (e.g., "I support what the messages on the PSA were trying to accomplish") on four 7-point Likerttype scales ( 1 = "strongly disagree," through 7 = "strongly agree"), and assess their behavioral intention to accept the messages' argument (e.g., "I plan to act in ways that are consistent with the position advocated by the PSAs messages") on three 7point Likert-type scales ( 1 = "strongly disagree," through 7 = "strongly agree"), which were adopted from Shen and Dillard (2007)'s study (Cronbach's $\alpha=0.98$ and Cronbach's $\alpha=0.97$, respectively).

\section{Data Analysis}

\section{Manipulation Check}

A 2 (Level of Fear Appeal: High vs. Low) X 2 (Perceived Self-Efficacy: High vs. Low) analysis of variance (ANOVA) is performed to assess the effectiveness of the fear appeal manipulation. The results indicate a statistically significant difference in participants' perceptions of level of fear appeal, $F(1,98)=17.82, p$ $<0.01$, partial $\eta^{2}=0.15$, but no significant main effect of perceived self-efficacy, $F(1,98)=0.02, p>0.05$, as well as the interaction between two independent variables, $F(1,98)=0.08, p>0.05$. The results show that participants in the high fear appeal condition evaluate the ads as relatively more fearful $(M=4.84, S E=$ $0.21)$ compared to participants' evaluations in the low fear appeal condition $(M=$ $3.56, S E=0.22$ ). 


\section{Level of Fears, Perceived Self-Efficacy, Perceived Impact, and Persuasion}

In terms of ratings for message effect on self versus average college students, the 2 X 2 ANOVA analysis reveals that the main effect of perceived self-efficacy, $F(1,98)=8.11, p<0.01$, partial $\eta^{2}=0.08$, is statistically significant, while the main effect of level of fear appeals is not significant, $F(1,98)=0.38, p>0.05$. In addition, a significant two-way interaction between two independent variables, $F$ $(1,98)=5.02, p<0.05$, partial $\eta^{2}=0.05$, is found. In the high fear condition, the Bonferroni post-hoc data results particularly show that participants with a low perception of self-efficacy $(M=0.41, S E=0.41)$ evaluate a higher TPP, whereas participants with a high self-efficacy evaluate a higher FPP $(M=-2.30, S E=0.49)$. However, in the low fear condition, both participants who have a high self-efficacy $(M=-1.44, S E=0.56)$ and participants who have a low self-efficacy $(M=-1.11$, $S E=0.51)$ evaluate a greater PSA impact on themselves than on others. Therefore, $\mathrm{H} 1 \mathrm{a}$ is supported in our findings.

In terms of attitudes toward messages, the 2 X 2 ANOVA analysis shows the significant main effect of perceived self-efficacy, $F(1,98)=17.32, p<0.01$, partial $\eta^{2}=0.15$, as well as the two-way interaction between independent variables, $F(1,98)=5.02, p<0.05$, partial $\eta^{2}=0.05$. In particular, participants with high self-efficacy $(M=5.91, S E=0.20)$ express more positive attitudes toward the presented messages than participants with low self-efficacy $(M=4.71$, $S E=0.21)$ regardless of a level of fear in the PSAs. Additionally, the post hoc test comparison reveals that the two-way interaction between two independent variables significantly influences attitudes toward messages. Especially, in the condition of high fear, participants with a low self-efficacy $(M=4.17, S E=0.31)$ evaluate the message less positively than participants with a high self-efficacy $(M$ $=6.01, S E=0.26)$. In contrast, when the messages convey low fear-arousing attributes, participants show positive attitudes toward messages regardless of their self-efficacy $\left(M_{\text {high }}=5.80, S E=0.30 ; M_{\text {low }}=5.25, S E=0.28\right)$. In relation to behavioral intention to accept the recommendation, a similar pattern is also observed where the main effect of perceived self-efficacy, $F(1,98)=25.66, p<$ 0.01 , partial $\eta^{2}=0.21$, and the two-way interaction effects are significant, $F(1,98)$ $=5.19, p<0.05$, partial $\eta^{2}=0.05$. In terms of participants' self-efficacy, participants with a high efficacy $(M=5.86, S E=0.19)$ express more intention to adopt the recommendation than participants with a low self-efficacy $(M=4.50, S E$ $=0.19$ ). Moreover, the additional post hoc tests confirm that participants with a high self-efficacy evaluate a greater intention to adopt the recommended behavior $(M=6.09, S E=0.25)$ than participants with a low self-efficacy $(M=4.12, S E=$ 0.29), under a high-fear condition. Under a low-fear condition, participants however evaluate their intention to adopt the message recommendation alike regardless of their levels of self-efficacy $\left(M_{\text {high }}=5.62, S E=0.28 ; M_{\text {low }}=4.87, S E\right.$ $=0.26$ ). Therefore, H1b is also supported by our data. 


\section{Discussion}

This study investigates whether an interaction between what people believe and what the messages present can make college students perceive a different PSA impact on themselves and on others. For decades, numerous studies have mainly focused on explaining the self-other perceptual gaps itself and have an effort to integrate diverse theories to explain how third-person perception (TPP) and firstperson perception (FPP) occur. Using the Extended Parallel Process Model's (EPPM) rationale, this research contributes further to knowledge about TPP and FPP regarding the psychological mechanism that leads to an inconsistent pattern of perceived media impacts in the context of socially desirable health campaigns.

\section{Modeling the TPP and FPP Judgment Mechanism in the Fear-Arousing PSA Context}

Overall, our findings suggest that high fear-arousing messages could complicate a participant's feelings toward the messages and make people tend to be more involved in unique defensive activities. Keller and Block (1999) argue that people have a strong tendency to adhere to their beliefs, so that they tend to discount a message's quality if it is incompatible with their beliefs/motivations. Indeed, this argument coincides with our findings in a high-fear condition. In particular, participants with a low self-efficacy tend to engage in fear control in response to high fear; thus, they evaluate that a perceived impact of PSA is greater on others than on themselves, and, simultaneously, they evaluate their attitudes and behavioral intention less positively. Several scholars indicate that the presence of fearful and vivid graphic descriptions of possible outcomes of not adopting a recommended behavior tends to cause a counterproductive outcome (Hale \& Dillard, 1995; Witte \& Allen, 2000) because of psychological defensiveness toward a fear (Brown, 2001). Indeed, empirical studies on the Extended Parallel Process Model (EPPM) note that people who engage in fear control show a greater tendency to undervalue the importance of the message and express reactions against the message (McMahan et al., 1998; Witte, 1994). In accordance with this EPPM discussion, our findings therefore show the possibility that participants who have a low self-efficacy may perceive the severe consequences of alcohol consumption as exaggerated due to psychological defensiveness. When message receivers perceive that the persuasive message is being manipulated or exaggerated to persuade them, as scholars note, they are more likely to feel anger and avoid accepting message arguments (Dillard \& Peck, 2001). In this sense, it makes sense that the high fear-low efficacy group shows TPP rather than FPP in the context of PSAs.

In contrast, participants with a high self-efficacy show the least fear control toward a high fear, and thus, they perceive a greater PSA impact on themselves than on others and express intention to adopt the recommendation more positively. One of the possible explanations of the FPP in the high fear-high efficacy group is people's level of self-protective motivations (Lopes, 1987). For instance, participants who are confident to control their alcohol consumption may have a high risk-avoidance motivation that makes them evaluate a threat as severe and 
applicable (Witte, 1992, 1994). For that reason, those individuals may seek more reasons to stay away from possible negative health threats and perceive the recommended action to be effective in preventing the potential threats. To this point, participants with a high self-efficacy may develop a less fear control and a greater acceptance of the PSAs that contain information consistent with their belief or behavior. Likewise, such positive message effects on the self can occur when the message is matched with a person's readiness to change his/her behavior. Empirical studies on health communication demonstrate that a certain targeted message is perceived as more valuable and relevant than others depending on how much individuals are ready to change their behaviors (Cho, 2006). Applying this notion to the current findings of FPP, it is possible that participants who have a high self-efficacy are more ready to change their alcohol consumption behaviors. Therefore, those individuals might believe that such high fear-arousing messages are more necessary for themselves and thus be motivated to consider the recommendation in the PSAs. Given the important role of perceived self-efficacy in the evaluation of health-related messages, future studies therefore need to investigate whether people's readiness to change the behavior and self-protection motivations are also related to the reduction of the first-person perception, underestimating the effects on self, in the context of PSAs.

Regarding the similar pattern of participants' TPP, FPP, and attitudes/ behaviors consequences, our study findings indicate that the perceived message effects on others/self could be relevant to the message persuasion. Studies on the third-person effects have stated that people tend to express a greater level of support for the media content regulations or participation in social activities if they perceive a greater perceptual gap between self and others in terms of media impact (Davison, 1983; Gunther, 1995). Similarly, one empirical investigation demonstrates that perceived media effectiveness could work as a causal antecedent to actual impacts in the persuasion process (Dillard, Shen, \& Vail, 2007). In this point, we suggest that people's TPP and FPP can be used as useful proxies to estimate the actual behavioral consequence in campaign effectiveness research. Considering this possibility, we are concerned about the possibility that participants who are less confident to accept the recommendation may show a decrease of acceptance of the message claims and a low involvement in subsequent activities in response to a high fear. We therefore suggest continued research that is aimed at better understanding of individuals' unique characteristics and the message elements that may affect their perceptions and actual behaviors to enhance the effectiveness of public health campaign.

\section{Practical Implications for Public Health Campaigns}

Despite the existence of numerous and varied alcohol abuse prevention campaigns, campaign planners still have a hard time devising effective strategies to persuade young adults who do not generally realize the serious consequences of binge drinking, and pay little attention to the health messages (Pilling \& Brannon, 2007). As our findings suggest, different individuals' self-efficacy can also make people perceive certain information to be less acceptable than others. Therefore, health-related campaign planners or health practitioners need to identify their 
primary targets' interest/status/belief about a certain health-related behavior and provide the information that the target audience wants to know. In particular, Gore and Bracken (2005) suggest that communicators design the health risk messages after estimating a person's Risk Behavior Diagnosis scale (RBD). The RBD scale (Witte, 1996) is frequently adopted in health communication literature to assess participants' attitude toward the severity of threat, their self-efficacy toward a certain health risk, and their subsequent fear control or danger control responses after exposure to a high health risk message (Gore \& Bracken, 2005). Therefore, after assessing the target audience's RBD, the campaign planners can adjust the health risk message, which enhances adaptive responses. Moreover, empirical reports underscore the need to tailor PSA messages in a way that individuals can relate to the message content (Rimal \& Adkins, 2003). For example, in the context of anti-binge drinking campaigns, participants who are exposed to targeted messages that address their specific fears about the consequences of alcohol consumption (e.g., skin damage) and subsequent reasons why they should change their drinking behaviors are more likely to reduce their own consumption of alcohol (Miller, Sovereign, \& Krege, 1988). Furthermore, scholars note that fear appeals can enhance the effectiveness of health risk messages when presenting the threat with information about possible feasible treatment (Gore \& Bracken, 2005). Therefore, if a fear appeal is selected as the campaign appeal to promote a certain health issue, it can be beneficial to provide additional information in a PSA that underscores the easiness of adopting recommended behaviors, as well as their benefits to reduce the severity of a health risk.

\section{Limitations and Suggestions for Future Studies}

While we purposely include artificial stimuli for this study and recruit a convenient sample, it will be beneficial to explore the effect of real PSAs with a broader population to enhance the external validity of these findings. Furthermore, to expand our understanding of TPP and FPP, it would be helpful to investigate how people describe their thoughts of the fear-arousing messages through a thought list that might help us to identify the reasons for their reactions. Although the current research provides an important insight into how negative responses arise from fear appeals in the context of anti-binge drinking, more examination with diverse topics and different types of appeals included in PSAs can expand our knowledge of health risk message effectiveness. Lastly, we have divided participants into two groups, a high self-efficacy group and a low self-efficacy group, through a median split technique, to examine the role of self-efficacy in the process of fear-arousing health message. Future studies however might examine a similar topic with more sophisticated methods, such as grouping or manipulation of participants' prior state considering the current advancement in the methodology.

In conclusion, the EPPM's rationale offers guidance to understand inconsistent pattern of FPP in the context of health risk messages and have important theoretical implications in relation to TPP and FPP. Particularly, the EPPM indicates the importance of understanding a condition that could promote 
maladaptive responses and reduces a person's perceived message effects on self versus others in the context of PSAs. Although health-related campaigns primarily attempt to deliver a socially meaningful and convincing message, all campaigns cannot expect success. On the basis of our findings, we note that increasing the perceived threat by presenting high fear-arousing techniques are effective for some segments of participants in this study, but not for all the participants. Therefore, if campaign planners strive to enhance health risk message acceptance among the public, they should consider how to improve the campaigns through a combination of certain message attributes as well as target audiences' attributes.

\section{References}

Brown, S. L. (2001). Emotive health advertising and message resistance. Australian Psychologist, 3, 193-199.

Cauberghe, V., De Pelsmacker, P., Janssens, W., \& Dens, N. (2009). Fear, threat and efficacy in threat appeals: Message involvement as a key mediator to message acceptance. Accident Analysis \& Prevention, 41(2), 276-285.

Cho, H. (2006). Readiness to change, norms, and self-efficacy among heavy-drinking college students. Journal of Studies on Alcohol, 67(1), 131-138.

Cho, H., \& Boster, F. J. (2008). First and third person perceptions on anti-drug ads among adolescents. Communication Research, 35(2), 169-189.

Cho, H., \& Han, M. (2004). Perceived effect of the mass media on self vs. other: A cross-cultural investigation of the third-person effects. Public Opinion Quarterly, $52,161-173$.

Chock, T. M., Fox, J. R., Angelini, J. R., Lee, S., \& Lang, A. (2003). Pacing and arousing content effects on personal impact, third person effects, and reverse third person effects of anti-smoking PSAs for smokers and non-smokers. Paper presented at the Annual Conference of the Association for Education in Journalism and Mass Communication, Kansas City, MO.

Chock, T., \& Lee, S. (2005). The impact of appeal type and message structure on first person and third person judgments of PSAs. Paper presented in the International Communication Association conference, New York, NY.

Cohen E. L., Shumate, M. D, \& Gold, A. (2007). Anti-smoking media campaign messages: Theory and practice. Health Communication, 22, 91-102.

Davison, W. P. (1983). The third-person effect in communication. Public Opinion Quarterly, 47, 1-15.

Dillard, J. P., \& Anderson, J.W. (2004). The role of fear in persuasion. Psychology \& Marketing, 21, 909-926.

Dillard, J. P., Shen, L., \& Vail, R. G. (2007). Does perceived message effectiveness cause persuasion or vice versa? 17 consistent answers. Human Communication Research, 33(4), 467-488.

Dillard, J. P., \& Peck, E. (2001). Persuasion and the structure of affect: Dual systems and discrete emotions as complementary models. Human Communication Research, 27, 38- 68.

Duck, J. M., \& Mullin, B. A. (1995). The perceived impact of mass media: Reconsidering the third-person effect. European Journal of Social Psychology, 25(11), 77-93. 
Duck, J., Terry, D., \& Hogg, M. (1995). The perceived influence of AIDS advertising: Third person effects in the context of positive media content. Basic and Applied Social Psychology, 17(3), 305-325.

Edwards, K., \& Smith, E. E. (1996). A disconfirmation bias in the evaluation of arguments. Journal of Personality and Social Psychology, 71(1), 5-24.

Freimuth, V. S., Hammond, S. L., Edgar, T., \& Monahan, J. L. (1990). Reaching those at risk: A content analytic study of AIDS PSA's. Communication Research, 17, 775-791.

Gore, T. D., \& Bracken, C. C. (2005). Testing the theoretical design of a health risk message: Reexamining the major tenets of the extended parallel process model. Health Education \& Behavior, 32(1), 27-41.

Gunther, A. C. (1991). What we think others think: Cause and consequences in thirdperson effect. Communication Research, 18, 355-372.

Gunther, A. C. (1995). Overrating the X-rating: The third-person perception and support for censorship of pornography. Journal of Communication, 45(1), 27-38.

Gunther, A. C., \& Hwa, A. P. (1996). Public perceptions of television influence and opinions about censorship in Singapore. International Journal of Public Opinion Research, 8, 248- 265.

Gunther, A. C., \& Mundy, P. (1993). Biased Optimism and the 3rd-person effect. Journalism Quarterly, 70(1), 58-67.

Hale, J. L., \& Dillard, J.P. (1995). Fear appeals in health promotion campaigns: Too much, too little, or just right? In E. W. Maibach, \& R. L. Parrot (Eds.), Designing health messages: Approaches from communication theory and public health practice (pp. 65-80). New York: Sage.

Hale, I. L., Lemieux, R., \& Mongeau, P. A. (1995). Cognitive processing of fear- arousing message content. Communication Research, 22(4), 459-474.

Henriksen, L., \& Flora, J. (1999). Third-person perception and children: Perceived impact of pro and anti-smoking ads. Communication Research, 26(6), 643-665.

Hoffner, C., \& Buchanan, M. (2002). Parents' responses to television violence: The third-person perception, parental mediation and support for censorship. Media Psychology, 4, 231-252.

Hoorens, V., \& Ruiter, S. (1996). The optimal impact phenomenon: Beyond the third-person effect. European Journal of Social Psychology, 26(4), 599-610.

Janz, N. K., \& Becker, M. H. (1984). The health belief model: A decade later. Health Education Quarterly, 11, 1-47.

Keller, P. A., \& Block, L. G. (1999). The effect of affect-based dissonance versus cognition-based dissonance on motivated reasoning and health-related persuasion. Journal of Experimental Psychology, 5(3), 302-313.

King, K. W., \& Reid, L. N. (1990). Fear arousing anti-drinking and driving PSAs: Do physical injury threats influence young adults? Journal of Current Research and Issues in Advertising, 12, 155-175.

Leshner, G., Bolls, P., \& Thomas, E. (2009). Scare 'em or disgust 'em: The effects of graphic health promotion messages. Health Communication, 24(5), 447-458.

Lopes, L. L. (1987). Between hope and fear: The psychology of risk. Advances in Experimental Social Psychology, 20(3), 255-295.

McKenna, J. W., \& Williams, K. N. (1993). Crafting effective tobacco counter advertisements: lessons from a failed campaign directed at teenagers. Public Health Reports, 108(1), 85-89.

McMahan, S., Witte, K., \& Meyer, J. A. (1998). The perception of risk messages regarding electromagnetic fields: extending the extended parallel process model to an unknown risk. Health Communication, 10(3), 247-259. 
Miller, W. R., Sovereign, R. G., \& Krege, B. (1988). Motivational interviewing with problem drinkers: The drinkers' check-up as a preventive intervention. Behavioral Psychotherapy, 16, 251-268.

Perloff, R. M. (1999). The third-person effect: A critical review and synthesis. Media Psychology, 1(4), 353-378.

Perloff, R. M. (2003). The dynamics of persuasion (2nd Ed.). Mahwah, NJ: Erlbaum.

Pilling, V. K., \& Brannon, L. A. (2007). Assessing college students' attitude toward responsible drinking messages to identify promising binge drinking intervention strategies. Health Communication, 22(3), 265-276.

Rimal, R. N., \& Adkins, A. D. (2003). Using computers to narrowcast health messages: The role of audience segmentation, targeting, and tailoring in health promotion. In T. L. Thomason, A. M. Dorsey, K. I. Miller, \& R. Parrott (Eds.), Handbook of health communication (pp. 497-513). Mahwah, NJ: Erlbaum.

Rojas, H., Shah, D. V., \& Faber, R. J. (1996). For the good of others: Censorship and the third-person effect. International Journal of Public Opinion Research, 8, 163-186.

Salwen, M. B. (1998). Perceptions of media influence and support for censorship: The third-person effect in the 1996 presidential election. Communication Research, 25, 259-285.

Shen, L., \& Dillard, J. P. (2007). The influence of behavioral inhibition/approach systems and message framing on the processing of persuasive health messages. Communication Research, 34(4), 433-467.

Snyder, L., \& Rouse, R. (1992). The media do not have only an impersonal impact: The case of AIDS risk perceptions and behavior. Paper presented in the International Communication Association, Miami, FL.

Stretcher, V., DeVellis, M., Becker, M., \& Rosenstock, I. (1986). Self-efficacy and the health belief model. Health Education Quarterly, 13, 73-92.

Ten Hoor, G. A., Peters, G. J. Y., Kalagi, J., de Groot, L., Grootjans, K., Huschens, et al. (2012). Reactions to threatening health messages. BMC Public Health, 12(1), 1-8.

Tucker, J. S., Ellickson, P. L., \& Klein, D. J. (2002). Smoking cessation during the transition from adolescence to young adulthood. Nicotine \& Tobacco Research, 4(3), 321-332.

Witte, K. (1992). Putting the fear back into fear appeals: The extended parallel process model. Communication Monographs, 59, 329-349.

Witte, K. (1994). Fear control and danger control: A test of the extended parallel process model (EPPM). Communication Monographs, 61, 113-134.

Witte, K. (1996). Predicting risk behaviors: Development and validation of a diagnostic scale. Journal of Health Communication, 1(4), 317-342.

Witte, K. \& Allen, M. (2000). A meta-analysis of fear appeals: Implications for effective public health campaigns. Health Education \& Behavior, 27, 591-615.

Witte, K., Meyer, G., \& Martell, D. (2001). Effective health risk messages: A step-by-step guide. Thousand Oaks, CA: Sage.

Wong, N. C. H., \& Cappella, J. N. (2009). Antismoking threat and efficacy appeals: Effects on smoking cessation intentions for smokers with low and high readiness to quit. Journal of Applied Communication Research, 37(1), 1-20. 